- has a half-life of just 8 days but accumulates quickly in the thyroid gland, is still the major component of the emissions from the nuclear plant and remains the greatest acute radiation health threat to the public, says Richard Wakeford, an epidemiologist at the Dalton Nuclear Institute, University of Manchester, UK. Some of the radioactivity levels detected in food since the accident have been "pretty hefty", he adds.

One of the largest health impacts from Chernobyl has been the 6,000 or more cases of thyroid cancer, mostly affecting people who were children at the time of the accident. In most of these cases, people received high radiation doses through drinking milk from cows that had grazed on iodine-contaminated pasture. Children are particularly at risk because their thyroids are still developing and are more prone to radiation damage than adults' mature thyroids.

The Japanese authorities are distributing potassium iodide tablets in affected areas, and Williams says that this is a crucial precaution. The tablets swamp the thyroid with non-radioactive iodine, preventing uptake of the radioactive form. Japanese children may also have a cultural advantage that lowers their risk from radioiodine. Whereas the children of Chernobyl tended to be iodine-deficient, the Japanese diet, rich in fish and seaweed, is "one of the most iodine-rich diets in the world", says Williams. Milk is also far less important in the Japanese diet than it was for the rural populations around Chernobyl.

Radioiodine doses in the thyroids of children in the most contaminated areas are already being monitored by the Japanese authorities. Nature has learned that the first results of that survey show minimal thyroid doses in 946 children living in areas northwest of the plant, a region where some of the highest fallout over land has been reported. Measurements during 28-30 March found maximum doses of 0.07 microsieverts per hour. This would suggest that the children had received total doses of less than 100 microsieverts, many thousands of times lower than was received by people living in contaminated areas around Chernobyl. The results "seem reassuring that not much iodine-131 has got into children", says Wakeford, adding that if the food bans are being effective, "Japan will have got a grip on what is the major concern in this sort of situation".

Vadim Chumak, a health physicist at the Research Center for Radiation Medicine at the Academy of Medical Sciences of Ukraine in Kiev, who has coordinated Chernobyl health studies, says that Japanese radiation researchers should heed a key lesson from that disaster. Dose data are fleeting, he warns, and if they are not collected now, any eventual research would be much more prone to uncertainty. Dosimetric monitoring after Chernobyl was sub-standard, he says, "so in our research we had to invest enormous time and effort in the retrospective estimation of doses".

\title{
Japan's long road ahead
}

\section{Isotopes hint at more than a decade of clean-up at Fukushima.}

\section{BY GEOFF BRUMFIEL}

$\mathrm{I}$ came as no surprise when the Tokyo Electric Power Company (TEPCO) admitted last week that it will scrap its stricken Fukushima Daiichi reactors. After explosions, copious radioisotope leaks and a liberal dousing with sea water, the reactors are a write-off. But what will workers encounter when they finally start decommissioning the shattered plant?

On 11 March, a tsunami knocked out backup generators, preventing cooling water from circulating around the hot cores of reactors 1-3. The fuel rods inside began to warp, split and at least partially melt. Steam reacted with the rods' outer sheath of zirconium, creating hydrogen gas that caused a sequence of explosions (see Nature 471, 417-418; 2011).

But data from Japanese regulators and TEPCO suggest to some researchers that conditions inside the core could be far worse than a partial meltdown. Some believe that molten fuel may have flowed into the outer concrete containment vessel, whereas others suggest that nuclear chain reactions are still happening inside the fuel.

The most worrisome evidence comes from water found in a building next to reactor 1 . On 26 March, Japan's Nuclear and Industrial Safety Agency reported the

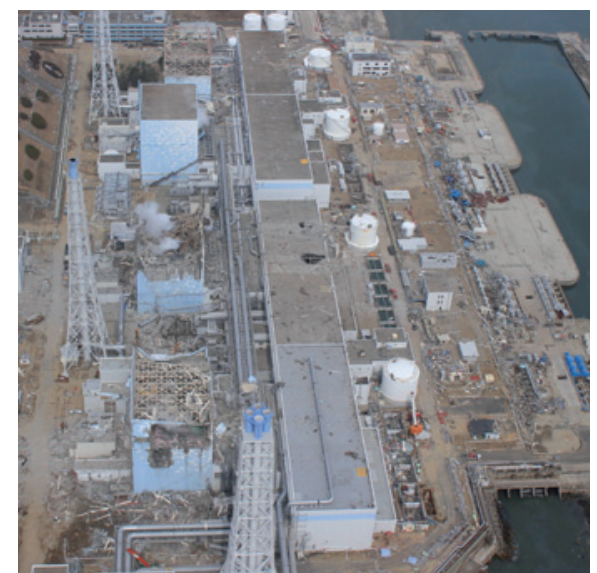

The damaged Fukushima Daiichi power plant.

presence of chlorine-38, a radioisotope with a half-life of just 37 minutes that forms when natural chlorine- 37 is hit by neutrons from fission. This could be evidence that fuel has clumped together into sufficiently large chunks to briefly restart nuclear reactions, says Ferenc DalnokiVeress, a physicist at the Monterey Institute of International Studies in California. Such bursts could put workers at extreme risk of radiation exposure during clean-up, he warns, and seriously complicate work at the site.

But Paddy Regan, a nuclear physicist at the University of Surrey in Guildford, UK, is sceptical. Other radioisotopes have a similar $\gamma$-ray spectrum and could be mimicking chlorine-38, he says, and TEPCO has already retracted erroneous measurements of other isotopes. Dalnoki-Veress agrees that the evidence is circumstantial, adding that he is frustrated by the lack of clear data coming from the plant.

Other theories also rest on tentative evidence. Richard Lahey, an emeritus professor of nuclear engineering at Rensselaer Polytechnic Institute in Troy, New York, believes that the core of reactor 2 may have melted its control rods, which are designed to stop nuclear reactions. Provisional pressure readings and high levels of radioactivity suggest to him that molten fuel has flowed through the control-rod system like lava and dripped into the containment vessel below, creating a clean-up nightmare.

The confusion recalls the weeks that followed the partial meltdown of a reactor at Three Mile Island in Pennsylvania in 1979. In the immediate aftermath of that emergency, the state of the reactor core was subject to "an ongoing debate that went on for months", recalls Jack DeVine, an independent nuclear consultant who spent six years cleaning up that accident.

Many scientists believed that the fuel rods at Three Mile Island were more-or-less intact, on the basis of computer models and simulations, says DeVine. But when a camera was finally lowered into the core in 1982, the damage was far worse than anyone had predicted. "It looked like my gravel driveway - a mess," he says. Engineers hoping to remove fuel rods in a process akin to conventional decommissioning of a nuclear core had to rethink their strategies.

It took 14 years to clear most of the fuel out of the reactor at Three Mile Island. Based on what he has seen so far, DeVine believes that decommissioning Fukushima will probably take longer. 